\title{
Pathological study of subchronic oral toxicity induced by Di (2- ethyl hexyl) phthalate in Japanese quails
}

\author{
S.S. Al-Mahmood ${ }^{1 *}$ and S.M. Al-Abady ${ }^{2}$ \\ ${ }^{1}$ Department of Pathology and Poultry Diseases, College of Veterinary Medicine, University of Mosul, Mosul, \\ ${ }^{2}$ Veterinary Doctor, Privet Sector, Sinjar, Iraq, Email: saevan981@yahoo.com
}

(Received April 25, 2017; Accepted July 7, 2017)

\begin{abstract}
In present study, we aimed to investigate the pathological changes induced by subchronic oral toxicity induced by sub lethal dose of Di (2-ethyl hexyl) phthalate (DEHP) in Japanese common quail. Forty male quails at one day old were divided randomly into two equal groups, the first group (treated group) was orally administrated by $10 \%$ of $\mathrm{LD}_{50}$ of DEHP (557.41 $\mathrm{mg} / \mathrm{kg}$ of body weight) for 42 days, while second group (control group) left without treatment throughout experiment period. The results of current study showed that there is congestion of kidney, microscopically they showed presence of hyaline degeneration in renal tubules, glomerulosclerosis, wide spread of degenerative and necrotic lesions in renal tubules, hemorrhage, infiltration of inflammatory cell especially macrophages and lymphocytes in interstitial tissue of kidney. While grossing of liver showed hepatomegaly with hemorrhage, microscopically the sections showed wide distributing of vacuolar degeneration (fatty change) in different size and shape of vacuoles in cytoplasm of affected hepatocytes, infiltration of inflammatory cells mainly macrophages and lymphocytes. In conclusion, the oral administration of DEHP at dose 557.41 $\mathrm{mg} / \mathrm{kg}$ of body weight for 42 days induced degenerative and necrotic irreversible changes in both kidney and liver of Japanese quail that affect their health and production.
\end{abstract}

Keywords: Pathology, Subchronic toxicity, DEHP, Quails, Kidney, Liver Available online at http://www.vetmedmosul.org/ijvs

$$
\begin{aligned}
& \text { دراسة مرضية للتسمم الفموي تحث المزمن المحدث بثنائي (؟ ـ اثيل هسكيل) فثالات في طيور } \\
& \text { سيقان سعد فاضل المحمود' و سعيد مجيد سعيد العبادي } \\
& \text { 'فرع الامر اض وامر اض الدواجن، كلية الطب البيطري، جامعة الموصل، الموصل، ׳طبيب بيطري، قطاع خاص، سنجار، العراق } \\
& \text { الخلاصة }
\end{aligned}
$$




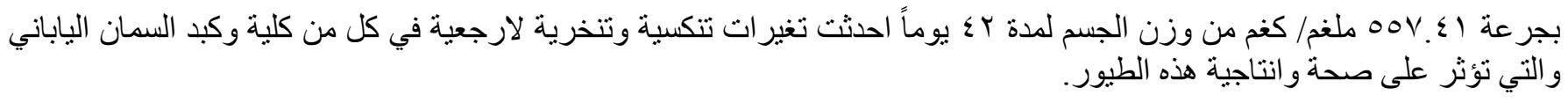

\section{Introduction}

Phthalates are mostly plasticizers used to give flexibility and strength to polyvinyl chloride (PVC) plastics (1). Generally, phthalates used as additives in food and personal care products (2), paints, lacquers, adhesive and printing inks (3).

Di (2-ethylhexyl) phthalates (DEHP) a widely-used plasticizer of phthalate esters characterized by colorless oily liquid that easily dissolved in water, blood and other fluids containing lipoproteins (4). DEHP was first created chemically in Japan at 1939 , now about $95 \%$ of DEHP is added to PVC as plasticizer (5). DEHP induced a global attention after many reports and studies about its toxicological potential and environment pollutants of both human and animals $(6,7)$. DEHP have highly affinity to be dissolved in water and blood, therefore many countries prevented medical devices to be manufactured from DEHP plasticized PVC plastics (8-11). The environment of breeding of Japanese quail contained many sources of DEHP plasticized PVC devices that liberate these plasticizers in environment that cause serious disease in other animals (12), even more the toxic pathological effect of DEHP in Japanese quails not investigated before and even the subchronic exposure to sub lethal dose of DEHP not established previously. Therefore, the current work aimed to study the pathological changes induced by subchronic oral administration of sub lethal dose of DEHP in common Japanese Quails Coturnix coturnix japonica.

\section{Materials and methods}

\section{Ethical statement}

All of the experimental procedures were conducted in accordance with the regulations of the College of Veterinary Medicine, University of Mosul, concerning protection of animals against cruelty.

\section{Experimental animals}

A total of 40 males of Japanese quails at one day old weighing $10-12 \mathrm{gm}$ were used in this work, they are maintained at 24 hours day at first three days of life then reduced to 20 hours day and 4 hours night cycle for the first week of age, later the day hours decreased by two hours weekly until fifth week of age were the light cycle is maintained at 12 hours day 12 hours night cycle. Quails were housed in clean properly ventilated caged free of DEHP plasticized PVC devices with clean litter made of wood with free access to food and water throughout the experiment period.

\section{Study groups}

At first day of age animals were divided into two groups as followed: Group I (DEHP treated group): a $10 \%$ of $\mathrm{LD}_{50}$ of DEHP were given via orogastric intubation once daily for 42 days from one day old of quails. Group II (Control group): left without any treatment throughout the whole period of experiment.

At the end of experiment time, all quails were euthanized using sharp knife by decapitation, after death specimens from tissue of kidney and liver were obtained for paraffin embedding with light microscopic examination.

\section{Histopathological study}

Samples of kidney and liver tissue were fixed in $10 \%$ neutral buffered formalin for 72 hours, dehydrated by descending concertation of ethyl alcohol, cleared by chloroform and xylene, infiltrated by hot paraffin wax at 58- $60{ }^{\circ} \mathrm{C}$, later these tissue samples were embedded in paraffin, sectioned at 4-6 $\mu \mathrm{m}$ and stained by routine Harris hematoxylin and eosin stain (H\&E) (13). Stained sections were examined with light microscopy at $40 \mathrm{x}$ and $400 \mathrm{x}$ magnification power (14).

\section{Chemical supply}

Di (2-ethylhexyl) Phthalate from Sigma - Aldrich company were used. DEHP were supplied as oily liquid of odor even colorless at purity of $99.50 \%$ with concentration of $0.995 \mathrm{gram} / \mathrm{ml}$ of supplied solution.

\section{Oral administrated dose}

A $10 \%$ of $\mathrm{LD}_{50}$ of DEHP were have been used, the $\mathrm{LD}_{50}$ were calculated by (15) at same age and weight, which is $5574.1 \mathrm{mg} / \mathrm{kg}$ of body weight and the toxic dose used in current work was $557.41 \mathrm{mg} / \mathrm{kg}$ of body weight in Japanese quails, and the size of administrating dose $0.250 \mathrm{ml} /$ quail. This dose calculated by dilution one milliliter of DEHP (contain $995 \mathrm{mg} / \mathrm{ml}$ ) in $10 \mathrm{ml}$ of distilled water.

\section{Results}

The results of current study showed that the gross examination of kidney reveled congestion of both kidneys which appears as red to black in color (figure 1-A), microscopically the kidney sections showed presence of hyaline degeneration in renal tubules with glomerulosclerosis (figure 1-B), also wide spread of degenerative and necrotic lesions in renal tubules hemorrhage (figure 1-C), these all these lesions caused loss of normal architecture of kidney tissue with infiltration of inflammatory cell especially macrophages and lymphocytes 
in interstitial tissue of kidney around affect renal tubules (figure 1-D).

While grossing of liver showed hepatomegaly with sub capsular hemorrhage (figure 2-A), microscopically the liver sections showed wide distributing vacuolar degeneration (fatty degeneration) in affected hepatocytes (figure 2-B), these lesions appear in different size and shape of well bounded washed vacuoles in cytoplasm of affected hepatocytes leading to pushing nucleus at cell edge given it ring like shape similar to fatty tissue (figure 2-C), these lesions observed with infiltration of inflammatory cells at centrilobular region (around central vein) mainly macrophages and lymphocytes (figure 2-D).

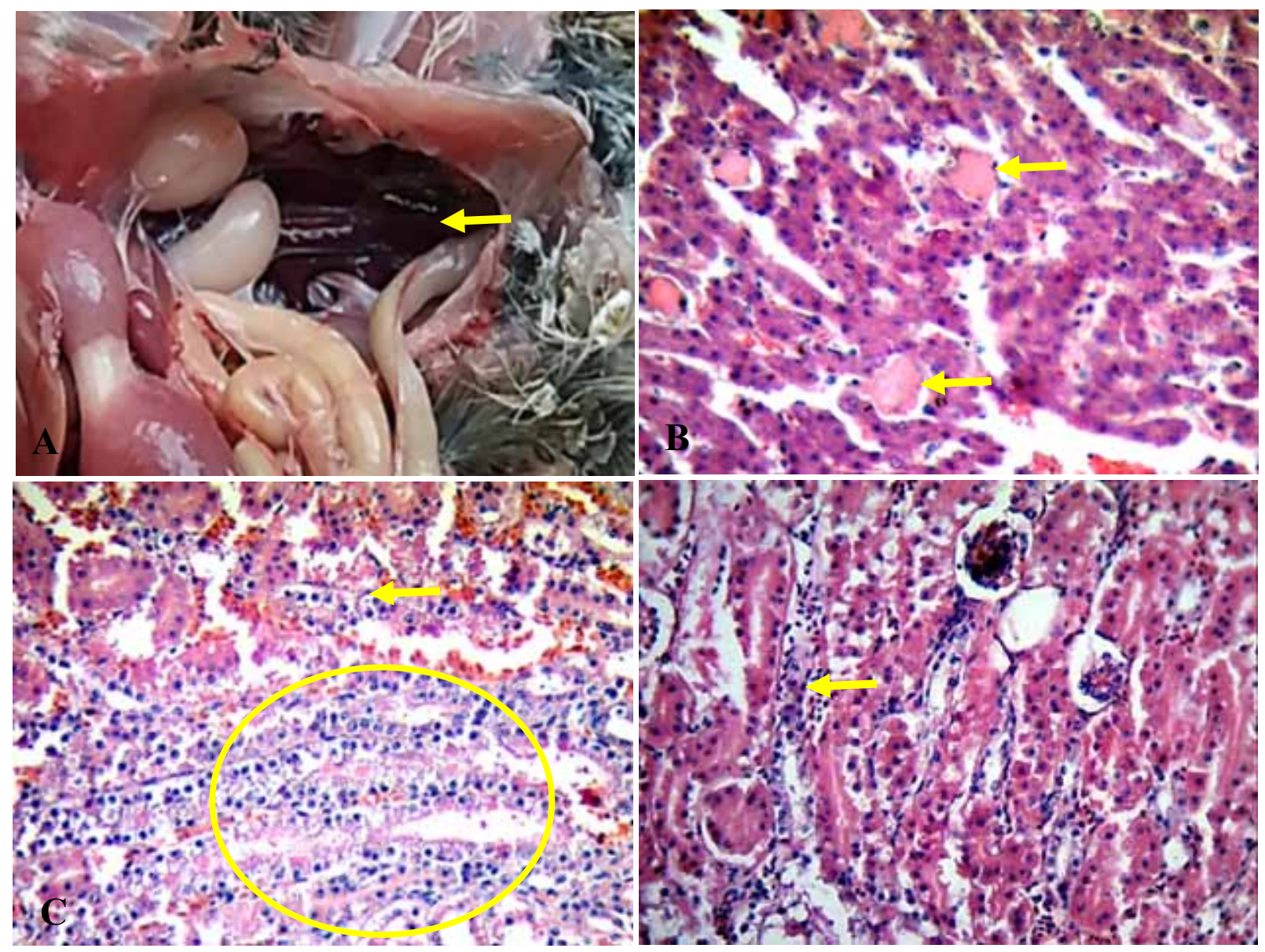

Figure 1: Quail kidney, after 42 day of oral administration of DEHP at dose of $557.41 \mathrm{mg} / \mathrm{kg}$. (A) Congestion of kidney (arrow). (B) Hyaline cast in lumen of renal tubules (arrow). 40x. HE. (C) Coagulative necrosis of renal epithelial cells (arrow) with vacuolar degeneration (circle). 400x. HE. (D) Infiltration of inflammatory cells especially macrophages and lymphocytes around affected renal tubules. 400x. HE.

\section{Discussion}

Kidney consider the main site for DEHP excretion while liver the site of metabolism after absorption from intestines (16), which explain the severity of pathological changes in these two tissues. in liver DEHP converted to mono (2ethylhexyl) Phthalate (MEHP) which is more toxic and more oxidative metabolite of DEHP (7). The result of current histopathological study was in agreement with other studies conducted in mice, rats and poultry exposed to
DEHP, in which there is degenerative and necrotic changes in renal tubules and hepatocytes $(12,17)$.

Glomerulosclerosis present in DEHP treated quails section occur due to continuous irritation by oxidative stress produced by both DEHP and MEHP that lead to inflammatory reaction with tissue destruction using deposition and formation of scar tissue in affected glomeruli with fibrosis lead to loss of function of these secretory units (18). 

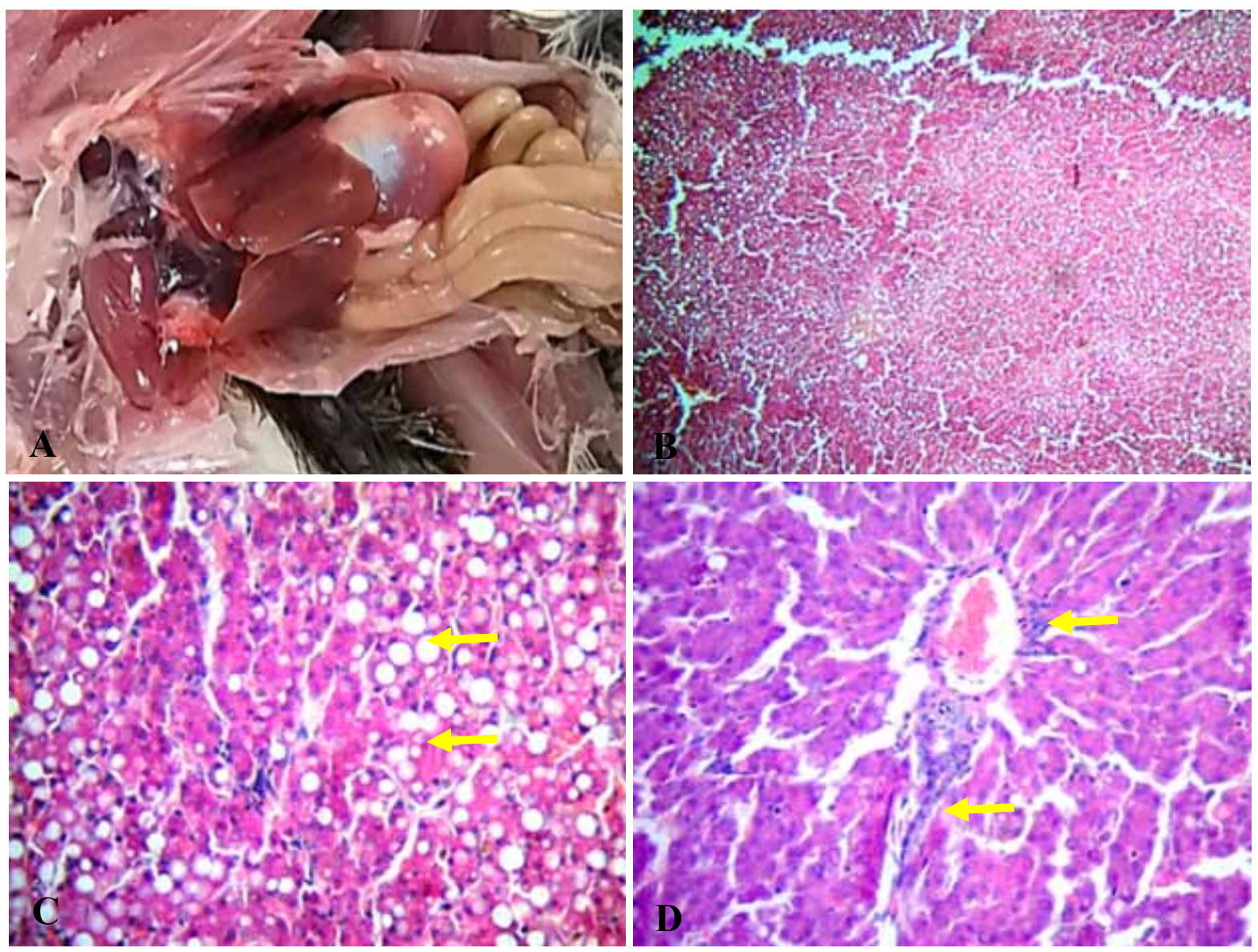

Figure 2: Quail liver, after 42 day of oral administration of DEHP at dose of $557.41 \mathrm{mg} / \mathrm{kg}$. (A) Hepatomegaly with hemorrhage. (B) Wide distribution of vacuolar degeneration in hepatocytes. 40x. HE. (C) High magnification of previous image (arrow). 400x. HE. (D) Infiltration of inflammatory cells at centrilobular (arrow). 400x. HE.

The vacuolation lesions observed in hepatocytes cytoplasm in quails administrated DEHP occur due to increase in lipid peroxidation that take place in hepatocytes, in which the DEHP and MEHP produce abundant generation of superoxide anion causing increase in lipid peroxidation, with time continuous elevated lipid peroxidation lead to cellular injury and changes in cell membrane permeability lead to failure of $\mathrm{Na}^{+}-\mathrm{K}^{-}$pump lead to influx of fluid inside hepatocytes which accumulated in form of vacuoles in addition to lipid that accumulated in vacuoles of cisterna from endoplasmic reticulum (19).

In addition to previous pathophysiological mechanism in hepatocytes, the exposure to DEHP lead to activation Peroxisomes Proliferating Activating Receptors (PPARs) that lead to increase in expression of gens that coding to different types of enzymes involve in fatty acids metabolism as palmitoyl- CoA oxidase, enoyl-CoA hydratase, carnitine acyltransferase and $\alpha$-glycerophosphate dehydrogenase, all these enzymes that increase in concentration in hepatocytes caused alteration in $\beta$ oxidation that lead to increase in fatty acid metabolism especially large and medium in hepatocytes that not coordinated with increase in conjugation with proteins to form lipoproteins that excreted from hepatocytes which accumulate in endoplasmic reticulum that secreted in well bounded vacuoles, also the increase of CoA above elimination level of free radicals by catalase lead to damages in hepatocytes DNA $(20,21)$.

The infiltration of inflammatory cells in both renal and hepatic tissue were noticed in current work due to production of IL-8 and IL-6 cytokines that released from exposed cells to DEHP and activated monocytes lead to chemical attraction of lymphocytes and macrophages (22).

In conclusion, the present study revealed that the subchronic oral toxicity of plasticizer DEHP in common Japanese Quails induced important degenerative and 
necrotic changes in both kidney and liver that interfere with health and production of these birds.

\section{References}

1. AgPU. Plasticizers Market Data. Arbeitsgemeinschaft PVC und Umwelt. Bonn, Germany. 2006;pp:200-219.

2. Petersen JH, Breindahl T. Plasticizers in total diet samples, baby food and infant formulae. Food Add Conta. 2000;17:133-141.

3. Wormuth M, Scheringer M, Vollenweider M, Hungerbühler K. What are the sources of exposure to eight frequently used phthalic acid esters in Europeans. Ris Anal. 2006;26:803-824

4. Strauss A. Di (2-ethylhexyl) phthalate (DEHP). J Pediatr Pharmacol Ther. 2004;9:89-95.

5. Afshari A, Gunnarsen L, Clausen PA, Hansen V. Emission of phthalates from PVC and other materials. Indoor Air. 2004;14:120128.

6. Luo H, Sun G, Shi Y, Shen Y, Xu K. Evaluation of the Di (2-ethyl hexyl) phthalate released from poly vinyl chloride medical devices that contact blood. J Sprin Plus. 2014;3(1):1-8.

7. Wittassek M, Angerer J. Phthalates: metabolism and exposure. Inter J Andro.2008;31:131-138.

8. BfArM Germany. Recommendations on the use of DEHP in medical devices. BfArM, Germany, 2004.

9. Commission E. The Safety of Medical Devices Containing DEHPPlasticizer PVC or Other Plasticizers on Neonates and Other Groups Possibly at Risk, Scientific Committee on Emerging and NewlyIdentified Health Risk. European Commission, 2008.

10. Health Canada. Draft Position Statement on DEHP in Medical Devices for Stakeholder Consultation, Health Canada, 2001.

11. U.S.FDA. Safety Assessment of Di (2-Ethylhexyl) Phthalate (DEHP) Released from PVC Medical Devices, Center for Devices and Radiological Health. US Food and Drug Administration, 2001.
12. Jarasova L, Harazim J, Suchy P, Knatka L, Stancova V. The distribution and accumulation of phthalate in the organs and tissues of chickens after the administration of feed stuff with different phthalate concentration. Vet Med. 2009;54(9):427-434.

13. Suvarna SK, Layuton C, Bancroft JD. Bancroft's theory and practice of histological techniques. 7th edition, Churchill Livingstone Press, New York- USA, 2013.

14. Luna LG. Manual of histological staining methods of the Armed Forces Institute of Pathology. $3^{\text {rd }}$ ed. The Blakiston Division, McGraw- Hill Book Company, New York, 1968.

15. Al-Mahmood SS, Al-Abady SM. Pathological Study of Acute Oral Toxicity Induced by Plasticizer Di (2- ethyl hexyl) Phthalate in Japanese Common Quails Coturnix coturnix japanies. Iraqi J Vet Med. 2017; accepted.

16. Ito $\mathrm{Y}$, Yokota $\mathrm{H}$, Wang $\mathrm{R}$, Yamanoshita $\mathrm{O}$, Ichihara G. Species differences in the metabolism of di(2-ethylhexyl) phthalate (DEHP) in several organs of mice, rats, and marmosets. Archiv Toxico. 2005;79:147-154.

17. Schrader M, Fahimi HD. Mammalian peroxisomes and reactive oxygen species. Histochem Cell Biolo. 2004;122:383-393.

18. Wei Z, Song L, Wei J. Maternal exposure to di- (2-ethylhexyl) phthalate alters kidney development through the renin-angiotensin system in offspring. Toxicol Lett. 2012;212:212-221.

19. Rusyn I, Peters JM, Cunningham ML. Modes of action and speciesspecific effects of di-(2-ethylhexyl) phthalate in the liver. Crit Rev Toxic. 2006;36:459-479.

20. Kambia N, Renault N, Dilly S, Farce A, Dine T. Molecular modelling of phthalates - PPARs interactions. J Enzyme Inhib Med Chem. 2008;23:611-616.

21. McGavin MD, Zachary JF. Pathological basis of veterinary disease. $4^{\text {th }}$ ed. Mosby, Elsevier, China. 2007;70-92.

22. Rizvi AA. Cytokine biomarkers, endothelial inflammation, and atherosclerosis in the metabolic syndrome: emerging concepts. Am J Med Sci. 2009;338:310-318. 